Check for updates

Cite this: Org. Biomol. Chem., 2020, 18, 2834

Received 5th February 2020,

Accepted 25th March 2020

DOI: 10.1039/d0ob00256a

rsc.li/obc

\section{Synthesis of orthogonally protected and functionalized bacillosamines $\uparrow$}

\author{
Jeanine van Mechelen, Jim Voorneveld, Hermen S. Overkleeft, Dmitri V. Filippov, iD \\ Gijsbert A. van der Marel (iD * and Jeroen D. C. Codée (iD *
}

\begin{abstract}
2,4-Diamino-2,4,6-trideoxyglucose (bacillosamine) is a monosaccharide found in many pathogenic bacteria, variation in the functionalities appended to the amino groups occurs depending on the species the sugar is derived from. We here report the first synthesis of bacillosamine synthons that allow for the incorporation of two different functionalities at the C-2-N-acetyl and C-4-amines. We have developed chemistry to assemble a set of conjugation ready Neisseria meningitidis C-2- $\mathrm{N}$-acetyl bacillosamine saccharides, carrying either an acetyl or $(R)$ - or (S)-glyceroyl at the C-4 amine. The glyceroyl bacillosamines have been further extended at the C-3-OH with an $\alpha$-D-galactopyranose to provide structures that occur as post-translational modifications of $\boldsymbol{N}$. meningitidis PilE proteins, which make up the bacterial pili.
\end{abstract}

\section{Introduction}

Bacillosamine (1, Bac, Fig. 1) is a characteristic bacterial monosaccharide that is present in various bacterial capsular polysaccharides and glycopeptides. ${ }^{1}$ It is a 2,4-diamino-2,4,6-trideoxyhexose (DATDH), that is most commonly functionalized with $N$-acetyl groups at C-2 and C-4 (2,4-di-NAcBac, 2). This residue is found at the reducing end of oligosaccharide chains of both $O$ - and $N$-linked glycoproteins of Campylobacter jejuni ${ }^{2}$ and Neisseria gonorrhoeae. ${ }^{3}$ Recently, a differently modified bacillosamine has been discovered in Neisseria meningitidis, ${ }^{4}$ where it is decorated, besides a single acetamide, with an $N$-glyceroyl group, thought to reside at the C4-amine (3, Fig. 1). ${ }^{5}$ This Bac-residue represents one of various posttranslational modifications (PTMs) that can occur on $N$. meningitides pilE proteins, the constituent protein monomers of the type IV pili. It can be further decorated with

Bioorganic synthesis group, Leiden University, Einsteinweg 55, 2333 CC Leiden, Leiden, The Netherlands. E-mail:jcodee@chem.leidenuniv.nl

$\dagger$ Electronic supplementary information (ESI) available: Synthetic procedures and experimental data. See DOI: 10.1039/d0ob00256a different mono- or disaccharides (see Fig. 1). The role of these PTMs is currently not known but it is clear that the type IV pili play an important role in the pathogenicity of the bacterium. Also, the exact structure of the Bac-residue present on the $N$. meningitides pili remains elusive as the stereochemistry of the glyceroyl group has not been established. ${ }^{5}$

To aid in the structure elucidation of the functionalized Bac residues in the $N$. meningitidis pili, its detection and the role of these differentially decorated bacillosamines in virulence, we reasoned that the availability of synthetic Bac-residues would provide powerful tools. We therefore set out to develop an effective route of synthesis for an orthogonally protected bacillosamine synthon, of which all functional groups can be site selectively addressed. We here report the first synthesis of such an orthogonally protected bacillosamine building block and we show the synthesis of spacer-equipped bacillosamines bearing different acyl functionalities (4b-4c, Fig. 1) and the extension of these towards a relevant conjugation-ready disaccharide (5, Fig. 1).

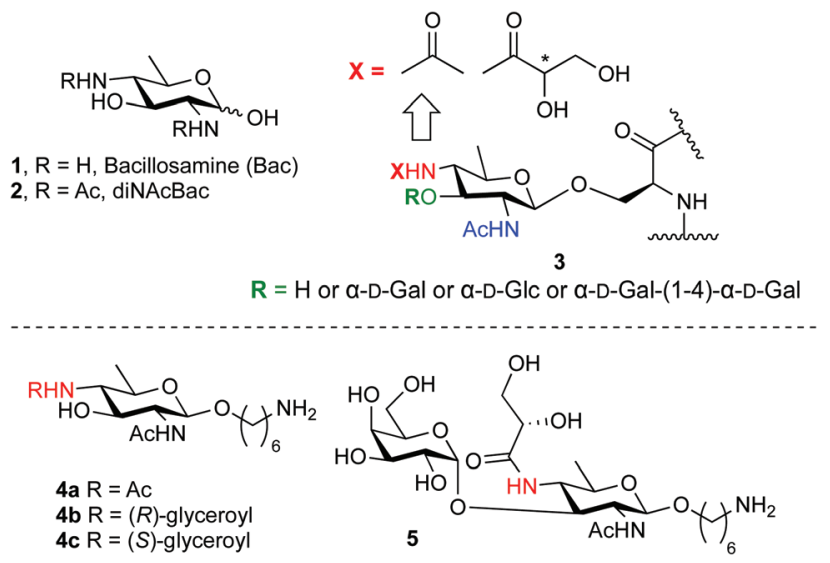

Fig. 1 Bacillosamine (1), di-N-acetylbacillosamine (2), bacillosamine PTMs found in $N$. meningitidis pili (3) and the synthetic targets of the current study (4 and 5 ). 


\section{Results and discussion}

Different syntheses of bacillosamine ${ }^{6}$ and bacillosamine containing oligosaccharides ${ }^{7}$ and glycopeptides ${ }^{8}$ have been reported, but none of these allow for the discrimination of the C-2 and C-4 amino groups and therefore the development of a new synthetic route was required. We thus set out to target key synthon 7, bearing two orthogonally protected amino groups at C-2 and C-4, as well as a 2-napthylmethyl ether that masks the $\mathrm{C}-3-\mathrm{OH}$ and an anomeric selenophenyl group for glycosylation purposes (see Scheme 1). Retrosynthetically, this building block can be derived from a suitably protected 6-deoxy galactosamine derivative $\mathbf{8}$, by a substitution reaction of the C-4-Omesylate. Selenophenyl galactosamine $\mathbf{8}$ can be readily accessed from D-fucal through an azidoselenation event ${ }^{9}$ and subsequent transformation of the azide into the protected C-2aminosugar.

Accordingly, 3,4-di-O-acetyl-D-fucal $\mathbf{9}^{10}$ was subjected to azidoselenation conditions to provide azidofucose $10^{11}$ (see Scheme 2). Saponification of the two acetates in $\mathbf{1 0}$ was then followed by regioselective installation of the C-3-naphthylmethyl ether and subsequent mesylation of the C-4-OH. Because we aimed to use azide as nucleophile for the introduction of the C-4-amine functionality, we had to transform the C-2-azide in $\mathbf{1 1}$ to achieve orthogonality. Although amines are commonly avoided during manipulations on carbohydrate building blocks, we reasoned that inorganic azide anion should be sufficiently nucleophilic to outcompete the C-2 amine in mesylate displacement. We therefore decided to reduce the azido group in $\mathbf{1 1}$ to the corresponding amine and invert the C-4-O-mesylate in the resulting fucosamine, without masking the C-2-amine. Thus, fucosazide 11 was exposed to 1,3-propanedithiol to deliver fucosamine 12, which was treated with $\mathrm{NaN}_{3}$ and $\mathrm{TBABr}$ in $\mathrm{DMF}$ at elevated temperature to provide the desired bacillosamine 13, bearing a fully orthogonal functional group pattern, in $81 \%$. Next, the C-2-amine was masked with a trichloroacetyl (TCA) group to provide fully protected bacillosamine 14. Reduction of the azide with 1,3propanedithiol then set the stage for the differentiation of the C-4-amino group into either an acetamide (towards 4 a) or the two glyceroyl substituted bacillosamines $\mathbf{4 b}$ and $\mathbf{4 c}$. During the reduction of the azide in 14, the TCA moiety was partially reduced as well to the corresponding C-2-dichloroacetamide (DCA), yielding compound 15. As the DCA group can be

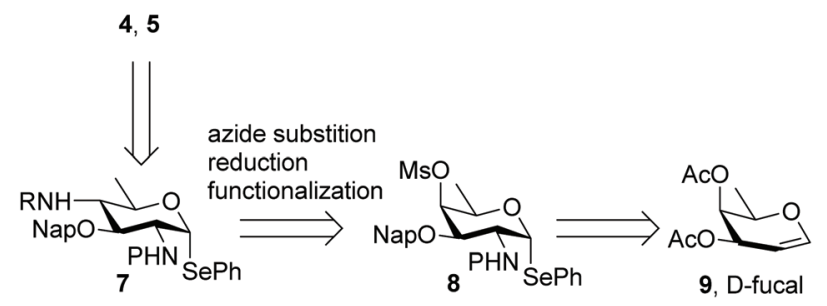

Scheme 1 Retrosynthetic analysis for the assembly of target compounds 4 and 5 .

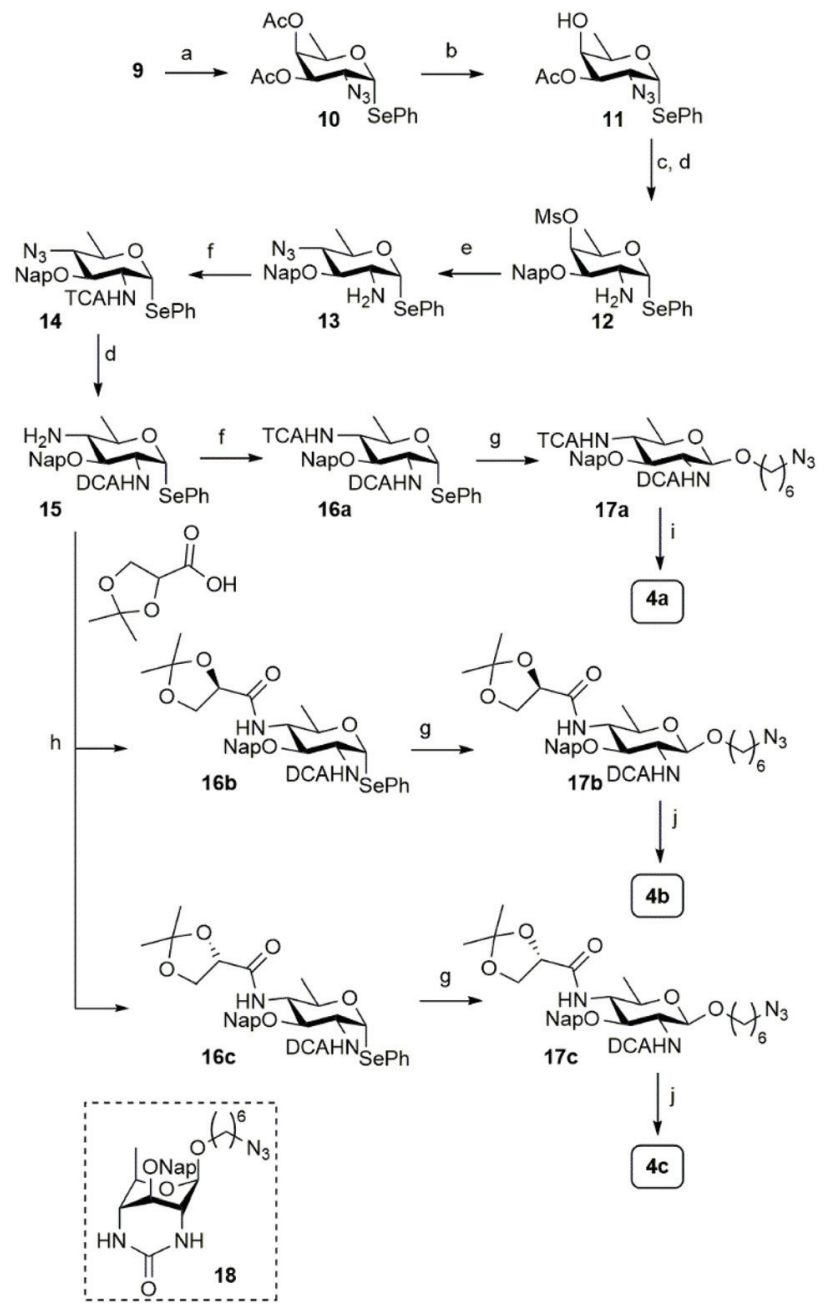

Scheme 2 Synthesis of differentially functionalized bacillosamines. Reagents and conditons: (a) $(\mathrm{PhSe})_{2}, \mathrm{Phl}(\mathrm{OAC})_{2}, \mathrm{TMS}-\mathrm{N}_{3}, \mathrm{DCM},-20{ }^{\circ} \mathrm{C}$ to rt., $93 \%$. (b) (i) $\mathrm{NaOMe}, \mathrm{MeOH}$. (ii) $\mathrm{Bu}_{2} \mathrm{SnO}$, toluene, $110^{\circ} \mathrm{C}$. (iii) $\mathrm{TBABr}$, $\mathrm{NapBr}, 82 \%$. (c) $\mathrm{MsCl}$, pyr. $0{ }^{\circ} \mathrm{C}$ to rt., $93 \%$. (d) 1,3-Propanedithiol, TEA, DMF, $92 \%$ for $12,82 \%$ for 15 . (e) $\mathrm{NaN}_{3}, \mathrm{TBABr}, \mathrm{DMF}, 80{ }^{\circ} \mathrm{C}, 81 \%$. (f) TCA-Cl, DCM : pyr., $0{ }^{\circ} \mathrm{C}, 89 \%$ for $14,88 \%$ for 16 a. (g) 6 -Azidohexanol, NIS, TMSOTf, DCM, $0{ }^{\circ} \mathrm{C}, 70 \%$ for $17 \mathrm{a}, 74 \%$ for $17 \mathrm{~b}, 74 \%$ for $17 \mathrm{c}$. (h) $2,2-$ Dimethyl-1,3-dioxolane-4-carboxylic acid ( $R$ for $16 \mathrm{~b}, S$ for $16 \mathrm{c}$ ), HCTU, DIPEA, DMF, $0{ }^{\circ} \mathrm{C}$ to rt., $83 \%$ for $16 \mathrm{~b}, 80 \%$ for $16 \mathrm{c}$. (i) $\mathrm{Pd}(\mathrm{OH})_{2} / \mathrm{C} 20 \mathrm{wt} \%$, $\mathrm{H}_{2}$. $\mathrm{H}_{2} \mathrm{O} / \mathrm{THF} / \mathrm{tBuOH}, 63 \%$. (j) (i) $\mathrm{H}_{2} \mathrm{O} / \mathrm{THF} / \mathrm{AcOH}, 80{ }^{\circ} \mathrm{C}$. (ii) $\mathrm{Pd}(\mathrm{OH})_{2} / \mathrm{C}$ 20 wt $\%, \mathrm{H}_{2}, \mathrm{H}_{2} \mathrm{O} / \mathrm{THF} / \mathrm{tBuOH}, 79 \%$ for $4 \mathrm{~b}, 81 \%$ for $4 \mathrm{c}$.

removed under similar conditions as the TCA, the synthetic strategy did not need any adjustment and we continued with $4-N$-acylation. Trichloroacetylation provided bacillosamine synthon 16a while reaction of the C-4-amine with either $R$ - or $S$-isopropylidene-glyceric acid under the agency of HCTU, provided bacillosamines $\mathbf{1 6 b}$ and 16c. Next, the three building blocks were equipped with an azidohexanol spacer, in glycosylation reactions promoted by $N$-iodosuccinimide (NIS) and trimethylsilyl trifluoromethanesulfonate (TMSOTf) to provide 17a, 17b and 17c. The products were obtained as single diastereoisomers and no oxazoline side products were detected, indicating that the dichloroacetyl groups provided effective 
anchimeric assistance. ${ }^{12}$ With the fully protected spacerequipped bacillosamines in hand, deprotection of the intermediates was undertaken. We first tried to unmask the TCA and DCA groups in 17a using $\mathrm{Cs}_{2} \mathrm{CO}_{3}$ in $\mathrm{DMF},{ }^{13}$ but this did not lead to the desired C-2,4-diamine. Instead bicyclic urea 18 was formed. ${ }^{14}$ We therefore switched to a hydrogenation reaction, aiming to unmask the spacer azide, C-2- $\mathrm{N}$-DCA, C-3-ONap and C-4- $N$-TCA groups in one step. After the first hydrogenation event using Pearlman's catalyst, LC-MS analysis of the crude reaction mixture revealed the presence of three chlorides and therefore the mixture was resubjected to the hydrogenation conditions until all chlorides had been removed. This delivered spacer-equipped di- $N$-acetyl bacillosamine $4 \mathbf{a}$ in $63 \%$ yield. After the acidic hydrolysis of the glyceroyl isopropylidene ketal in 17b and 17c, deprotection under the same conditions delivered the C-2- $N$-acetyl-C-4- $N$-glyceroyl bacillosamines $\mathbf{4 b}$ and $4 \mathrm{c}$ in $79 \%$ and $81 \%$ yield, respectively.

With a successful route of synthesis towards differentially functionalized bacillosamines established, we set out to probe the generation of a $N$. meningitidis disaccharides, featuring an additional $\alpha$-D-galactopyranose attached to the $\mathrm{C}-3-\mathrm{OH}$ of the bacillosamine. To install the required 1,2-cis-galactosyl linkage we used a 4,6-di-tert-butyl silylidene protected galactose donor 19 as 4,6-silylidene functionalized galactopyranosides are amongst the most reliable donors for the installation of cisgalactosyl linkages. ${ }^{15}$ Because the presence of amides in glycosyl acceptors can lead to problematic glycosylation reactions ${ }^{16}$ we decided to attach the $\alpha$-galactoside prior to the introduction of the $N$-glyceroyl. Thus, we prepared C-4-azide acceptor 20 by DDQ-mediated unmasking of the C-3-hydroxyl function in $\mathbf{1 4}$. In a chemoselective glycosylation reaction, imidate donor $19^{17}$ and bacillosamine selenoglycoside acceptor $\mathbf{2 0}$ were then reacted to provide, in a completely stereoselective manner, the desired disaccharide 21 in $91 \%$ yield. Before installation of the azidohexanol spacer, the C-4-N-glyceroyl groups had to be incorporated and we therefore reduced the C-4-azide in 21, which again led to the conversion of the C-2- $N$-TCA amide into the corresponding DCA-group. Amine 22 was obtained in 48\% yield and condensed with $(S)$-isopropylidene-glyceric acid using HCTU as the condensation agent to furnish the glyceroyl bacillosamine disaccharide 23 in $30 \%$. It was observed that both the reduction and the amide bond forming reactions proceeded significantly slower in the disaccharide than the corresponding reactions on the monosaccharides described above. This may be attributed to increased steric hindrance of the appended galactopyranose with the neighboring C4-nitrogen. Next the azidohexanol spacer was introduced using NIS/ TMSOTf to activate the seleno disaccharide to afford the fully protected disaccharide $\mathbf{2 4}$ in $57 \%$ yield. At this stage, all protecting groups in disaccharide $\mathbf{2 4}$ were removed by the following procedure. First, the silylidene group was removed by treatment of HF.Pyr in THF yielding the diol in 64\% yield. Next, the isopropylidene group in the glyceroyl moiety was hydrolysed with $\mathrm{AcOH} / \mathrm{H}_{2} \mathrm{O} / \mathrm{THF}$. Finally, the hydrogenation procedure, as described above, was undertaken to remove the benzyl ethers and transform the dichloroacetamide into the
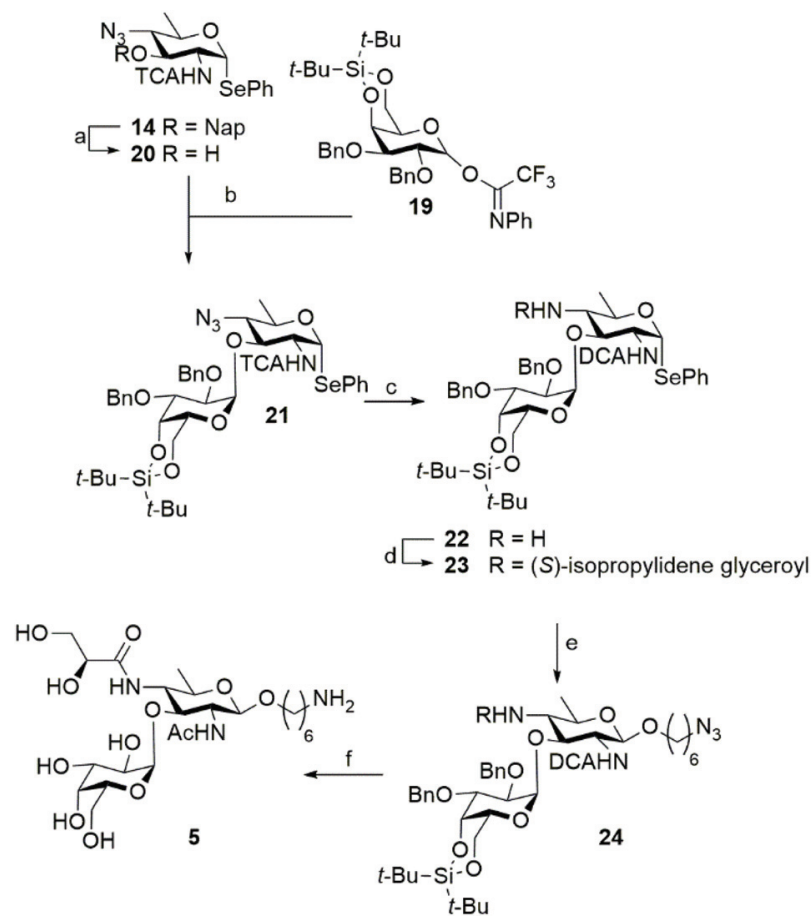

Scheme 3 Synthesis of galactosylated $\mathrm{C} 4-\mathrm{N}$-glyceroyl bacillosamines. Reagents and conditions: (a) $\mathrm{DDQ}, \mathrm{DCM} / \mathrm{H}_{2} \mathrm{O}, 80 \%$. (b) Compound 20, TMSOTf, DCM, $0{ }^{\circ} \mathrm{C}, 91 \%$. (c) 1,3-Propanedithiol, TEA, DMF, 48\%. (d) (S)-2,2-Dimethyl-1,3-dioxolane-4-carboxylic acid for, HCTU, DIPEA, DMF, $0{ }^{\circ} \mathrm{C}$ to rt., $30 \%$. (e) 6 -Azidohexanol, NIS, TMSOTf, DCM, $0{ }^{\circ} \mathrm{C}, 57 \%$, (f) i) $\mathrm{HF}$.pyr, $\mathrm{THF}, 64 \%$ (ii) $\mathrm{H}_{2} \mathrm{O} / \mathrm{THF} / \mathrm{AcOH}, 80^{\circ} \mathrm{C}$. (iii) $\mathrm{Pd}(\mathrm{OH})_{2} / \mathrm{C} 20$ wt\%, $\mathrm{H}_{2}, \mathrm{H}_{2} \mathrm{O} / \mathrm{THF} / \mathrm{tBuOH}, 41 \%$.

corresponding acetamide and the spacer azide into a primary amine. The hydrogenation reaction was monitored by LC-MS analysis, and repeated when required. In this manner disaccharide 5 was obtained in $41 \%$ yield (Scheme 3).

\section{Conclusions}

In conclusion, we have here disclosed the first synthesis towards an orthogonally protected bacillosamine synthon, that allows for the differentiation of the two amino functionalities, and its use in the generation of a $N$. meningitidis PilE disaccharide bearing a C-3- $\alpha$-D-galactose appendage and a C-4- $N$-glyceroyl. The chemistry developed here can be used to generate differentially functionalised bacillosamines and pave the way to the assembly of larger bacillosamine containing oligosaccharides as well as glycopeptides. The set of conjugation ready bacillosamines can be used to generate antibodies directed at these $N$. meningitidis PilE post-translational modifications for both therapeutic and diagnostic purposes.

\section{Conflicts of interest}

There are no conflicts to declare. 


\section{Acknowledgements}

This work was financially supported by The Netherlands Organization for Scientific Research (NWO).

\section{Notes and references}

1 N. Sharon, Glycobiology, 2007, 17, 1150-1155; E. Vinogradov, L. Nossova, A. Swierzko and M. Cedzyński, Carbohydr. Res., 2004, 339, 2045-2047.

2 N. M. Young, J. R. Brisson, J. Kelly, D. C. Watson, L. Tessier, P. H. Lanthier, H. C. Jarrell, N. Cadotte, F. St Micheal, E. Aberg and C. M. Szymanski, J. Biol. Chem., 2002, 277, 42530-42539.

3 F. E. Aas, A. Vik, J. Vedde, M. Koomey and W. EggeJacobsen, Mol. Microbiol., 2007, 65, 607-624; M. D. Hartley, M. J. Morrison, F. E. Aas, B. Borud, M. Koomey and B. Imperiali, Biochemistry, 2011, 50, 4936-4948.

4 E. Stimson, M. Virji, S. Barker, M. Panico, I. Blench, J. Saunders, G. Payne, E. R. Moxon, A. Dell and H. R. Morris, Biochem. J., 1996, 33, 29-33.

5 (a) J. Chamot-Rooke, G. Mikaty, C. Malosse, M. Soyer, A. Dumont, J. Gault, A. F. Imhaus, P. Martin, M. Trellet, G. Clary, P. Chafey, L. Camoin, M. Nilges, X. Nassif and G. Duménil, Science, 2011, 331, 778-782; (b) J. Gault, M. Ferber, S. Machata, A. F. Imhaus, C. Malosse, A. Charles-Orszag, C. Millien, G. Bouvier, B. Bardiaux, G. Péhau-Arnaudet, K. Klinge, I. Podglajen, M. C. Ploy and G. Duménil, PLoS Pathog., 2015, 1-24.

6 E. Bedini, D. Esposito and M. Parrilli, Synlett, 2006, 825830; E. Weerapana, K. J. Glover, M. M. Chen and B. Imperiali, J. Am. Chem. Soc., 2005, 127, 13766-13767.
7 M. N. Amin, A. Ishiwata and Y. Ito, Carbohydr. Res., 2006, 341, 1922-1929.

8 M. Emmadi and S. S. Kulkarni, Nat. Prod. Rep., 2014, 31, 870-879.

9 R. J. Roblez-Diaz, J. Org. Chem., 1993, 58, 6122-6125.

10 L. Somsák, I. Németh and J. Carbohydrate, Chem. - Eur. J., 1993, 12, 679-684.

11 (a) Y. V. Mironov, A. A. Sherman and N. E. Nifantiev, Tetrahedron Lett., 2004, 45, 9107-9110; (b) B. Hagen, S. Ali, H. S. Overkleeft, G. A. van der Marel and J. D. C. Codée, J. Org. Chem., 2017, 82, 848-868.

12 S. Kusumoto, K. Yamamoto, M. Imoto, M. Inage, M. Tsuijmoto, S. Kotani and T. Shiba, Bull. Chem. Soc. Jpn., 1986, 59, 1411-1417.

13 D. Urabe, K. Sugino, T. Nishikawa and M. Isobe, Tetrahedron Lett., 2004, 45, 9405-9407.

14 This product was not purified and therefore no yield has been determined. The spectroscopic data sufficed to establish the structure.

15 (a) A. Imamura, H. Ando, S. Korogi, G. Tanabe, O. Muraoka, H. Ishida and M. Kiso, Tetrahedron Lett., 2003, 44, 6725-6728; (b) A. Imamura, H. Ando, H. Ishida and M. Kiso, Org. Lett., 2005, 7, 4415-4418; (c) A. Imamura, A. Kimura, H. Ando, H. Ishida and M. Kiso, Chem. - Eur. J., 2006, 12, 8862-8870; (d) B. Hagen, J. H. M. van Dijk, Q. Zhang, H. S. Overkleeft, G. A. van der Marel and J. D. C. Codée, Org. Lett., 2017, 19, 2514-2517.

16 D. Crich and V. Dudkin, J. Am. Chem. Soc., 2001, 123, 68196825.

17 B. Liu, J. van Mechelen, R. J. B. H. N. van den Berg, A. M. C. H. van den Nieuwendijk, J. M. F. G. Aerts, G. A. van der Marel, J. D. C. Codée and H. S. Overkleeft, Eur. J. Org. Chem., 2019, 118-129. 